\title{
Protein lysine methylation contributes to modulating the response of sensitive and tolerant Arabidopsis species to cadmium stress
}

\author{
Nelson B. C. Serre ${ }^{1}$ (1) | Manon Sarthou ${ }^{1}$ | Océane Gigarel $^{1}$ | Sylvie Figuet ${ }^{1}$ | \\ Massimiliano Corso $^{2}$ (i) | Justine Choulet ${ }^{1}$ | Valérie Rofidal ${ }^{3}$ | Claude Alban ${ }^{1}$ |

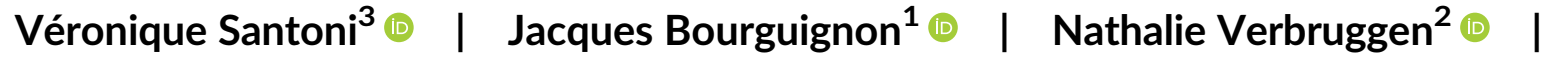 \\ Stéphane Ravanel ${ }^{1}$ @
}

${ }^{1}$ University of Grenoble Alpes, CEA, INRA, CNRS, IRIG, PCV, Grenoble, France

${ }^{2}$ Laboratory of Plant Physiology and Molecular Genetics, Université Libre de Bruxelles, Brussels, Belgium

${ }^{3}$ Biochimie et Physiologie Moléculaire des Plantes, Institut de Biologie Intégrative des Plantes, UMR 5004 CNRS/UMR 0386 INRA/ Montpellier SupAgro/Université Montpellier, Montpellier, Cedex 2, France

\section{Correspondence}

Stéphane Ravanel, University of Grenoble Alpes, CEA, INRA, CNRS, IRIG, PCV,

17 Avenue des Martyrs, 38000 Grenoble,

France.

Email: stephane.ravanel@cea.fr

\section{Present address}

Massimiliano Corso, Institut Jean-Pierre Bourgin, INRA, AgroParisTech, CNRS, University Paris-Saclay, F-78026 Versailles Cedex, France.

\section{Funding information}

Agence Nationale de la Recherche, Grant/ Award Number: ANR-10-LABX-49-01; Department of Plant Biology and Breeding of the Institut National de la Recherche Agronomique; Fondation de Coopération Scientifique Rovaltain; Fonds de la Recherche Scientifique-FNRS, Grant/Award Number: PDR T.0206.13; Région Auvergne RhôneAlpes; Toxicology Program of the Commissariat à l'Energie Atomique et aux Energies Alternatives

\begin{abstract}
The mechanisms underlying the response and adaptation of plants to excess of trace elements are not fully described. Here, we analysed the importance of protein lysine methylation for plants to cope with cadmium. We analysed the effect of cadmium on lysine-methylated proteins and protein lysine methyltransferases (KMTs) in two cadmium-sensitive species, Arabidopsis thaliana and A. lyrata, and in three populations of $A$. halleri with contrasting cadmium accumulation and tolerance traits. We showed that some proteins are differentially methylated at lysine residues in response to $\mathrm{Cd}$ and that a few genes coding KMTs are regulated by cadmium. Also, we showed that 9 out of $23 \mathrm{~A}$. thaliana mutants disrupted in KMT genes have a tolerance to cadmium that is significantly different from that of wild-type seedlings. We further characterized two of these mutants, one was knocked out in the calmodulin lysine methyltransferase gene and displayed increased tolerance to cadmium, and the other was interrupted in a KMT gene of unknown function and showed a decreased capacity to cope with cadmium. Together, our results showed that lysine methylation of nonhistone proteins is impacted by cadmium and that several methylation events are important for modulating the response of Arabidopsis plants to cadmium stress.
\end{abstract}

\section{KEYWORDS}

Arabidopsis halleri, Arabidopsis thaliana, cadmium, metal stress, methyltransferase, post-translational modification, protein methylation, response, tolerance 


\section{1 | INTRODUCTION}

As sessile organisms, land plants must deal with fluctuating levels of essential and non-essential trace elements in soils. Some plant species have the ability to colonize soils contaminated by toxic levels of metals and display remarkable leaf metal accumulation without visible toxicity symptoms. Understanding tolerance and accumulation of metals in these species, referred to as hyperaccumulators, offers the unique opportunity to uncover key mechanisms governing metal homeostasis and adaptation to challenging environments (for reviews, see Verbruggen, Hermans, \& Schat, 2009; Kramer, 2010). Arabidopsis halleri, a close relative of $A$. thaliana and $A$. lyrata, is a model species for studying tolerance and accumulation of cadmium ( $\mathrm{Cd}$ ), one of the most toxic metal for living organisms (for reviews, see Kramer, 2010; DalCorso, Fasani, \& Furini, 2013; Verbruggen, Juraniec, Baliardini, \& Meyer, 2013; Moulis, Bourguignon, \& Catty, 2014). While Cd and zinc tolerance seems to be constitutive in A. halleri, populations originating from different genetic units and from metallicolous or nonmetallicolous soils display important variability in terms of $\mathrm{Cd}$ accumulation (Corso et al., 2018; Meyer et al., 2015; Schvartzman et al., 2018; Stein et al., 2017). This intraspecific variability suggests adaptation at the local scale and, possibly, the involvement of different molecular mechanisms to account for metal accumulation and tolerance traits.

In the last 15 years, the combination of genetic, 'omics' and functional approaches in both tolerant and non-tolerant species have contributed considerably to the understanding of $\mathrm{Cd}$ toxicity, tolerance and accumulation. Key mechanisms involved in metal uptake, translocation, chelation with ligands, vacuolar sequestration and cell signalling have been characterized (for reviews, see Villiers et al., 2011; DalCorso et al., 2013; Clemens, Aarts, Thomine, \& Verbruggen, 2013; Clemens \& Ma, 2016). The coordination of these processes is accomplished through multilevel regulatory mechanisms, including the epigenetic, transcriptional and post-translational levels (Gallego et al., 2012; Haak et al., 2017). Despite recent progress, the role of posttranslational modifications (PTMs) in the response and adaptation of plants to $\mathrm{Cd}$ and other trace elements is still poorly documented. Given their pivotal role in the regulation of many cellular processes, it is anticipated that PTMs are important for plants to cope with biotic and abiotic stresses (Dahan, Koen, Dutartre, Lamotte, \& Bourque, 2011; Kosova, Vitamvas, Prasil, \& Renaut, 2011). To date, the most studied modification in the field of metal stress is protein phosphorylation. It has been shown that $\mathrm{Cd}$ poisoning in A. thaliana or Medicago sativa is accompanied by the activation of several mitogen-activated protein kinases (Jonak, Nakagami, \& Hirt, 2004; Liu et al., 2010) and SNF1-related protein kinases (Kulik et al., 2012). Also, it has been reported that $\mathrm{Cd}$ stress induces the hyper-phosphorylation of the eukaryotic translation initiation factor elF2a (Sormani et al., 2011) and the plasma membrane $\mathrm{H}^{+}$-ATPase (Janicka-Russak, Kabala, \& Burzynski, 2012). Metal stress is also responsible for changes in the pattern of PTMs on tubulin (Gzyl, Chmielowska-Bak, Przymusinski, \& Gwozdz, 2015). Finally, it is worth noting that the production of reactive oxygen species triggered by $\mathrm{Cd}$ is responsible for the carbonylation of proteins, an irreversible oxidative modification leading to the degradation of damaged proteins by the proteasome. Several studies indicated that plants treated with $\mathrm{Cd}$ display an increased oxidation of proteins (e.g., Pena, Barcia, Azpilicueta, Mendez, \& Gallego, 2012; RomeroPuertas, Palma, Gómez, Del Río, \& Sandalio, 2002) and an upregulation of the $20 \mathrm{~S}$ proteasome proteolytic pathway (e.g., Pena, Pasquini, Tomaro, \& Gallego, 2006; Polge et al., 2009; Sarry et al., 2006).

Protein methylation is a very diverse PTM acting on different protein residues. It is widespread in eukaryotic proteomes, modifying both histones and non-histone proteins, and contributes to the finetuned regulation of protein function. The modification of the lysine (Lys) side chain of proteins is among the most frequent methylation event (Falnes, Jakobsson, Davydova, Ho, \& Malecki, 2016; Lanouette, Mongeon, Figeys, \& Couture, 2014). It is catalysed by two structurally different classes of protein Lys methyltransferases (KMTs), the SET domain-containing group (SDG) and the seven-beta-strand (SBS) superfamily, which are able to add one to three methyl groups to specific Lys residues in proteins (Serre, Alban, Bourguignon, \& Ravanel, 2018). In plants, these enzymes have been shown to methylate histones and non-histone proteins involved in all aspects of cell biology (e.g., transcription, protein synthesis, metabolism). Protein Lys methylation can be reversible by the action of demethylases. Demethylases acting on non-histone Lys-methylated proteins have not been yet reported in plants (Serre et al., 2018).

The identification of the enzyme/substrate (KMT/protein) relationship is a critical step towards understanding the role of protein methylation (Falnes et al., 2016; Lanouette et al., 2014; Serre et al., 2018). As such, inactivating the genes coding KMTs is the best way to analyse the functional outcomes of methylation in vivo. Despite recent progress, the role of non-histone protein Lys methylation in regulating plant cellular functions is still limited (Serre et al., 2018). In particular, no information is available about the role of protein methylation in the response and adaptation of plants to metal stress. The present work is based on the assumption that this PTM could be important for plants to efficiently address stress situations induced by metals. This hypothesis is supported by the abundance and diversity of Lys-methylated proteins, possibly targeting components of metal transport, signalling pathways or detoxification machineries, and the recognized role of this modification in the regulation of protein function (Falnes et al., 2016; Lanouette et al., 2014). To test this hypothesis, we analysed the expression of the two main players involved in protein Lys methylation, that is, Lys-methylated proteins and genes coding KMTs, in three Arabidopsis species challenged with $\mathrm{Cd}$. We used $A$. thaliana and $A$. lyrata non-tolerant plants and three populations of $A$. halleri from different genetic units and showing contrasting tolerance and accumulation of Cd (Corso et al., 2018; Meyer et al., 2015; Schvartzman et al., 2018). First, we showed that some non-histone proteins are differentially methylated at Lys residues in response to $\mathrm{Cd}$ and we identified one of these proteins by MS/MS. Second, we showed that Cd stress has limited impact on the transcriptional regulation of KMT genes. Third, using a root growth inhibition assay with $A$. thaliana mutants disrupted in genes coding KMTs, we showed that nine out of 23 mutants have a tolerance to $\mathrm{Cd}$ that is different from that of wild-type seedlings. Finally, we 
characterized two of these mutants that are either more tolerant or more sensitive to $\mathrm{Cd}$. Together, our results showed that $\mathrm{Cd}$ triggers changes in the expression of a few Lys-methylated proteins and KMT genes, and that several Lys-methylating enzymes are important for modulating the response of Arabidopsis plants to $\mathrm{Cd}$ stress.

\section{2 | METHODS}

\section{1 | Plant material and growth conditions}

A. thaliana ecotype Columbia (Col-0), A. lyrata ssp. petraea (Linnaeus) O'Kane and Al-Shehbaz, and the Arabidopsis halleri ssp. halleri (Linnaeus) O'Kane and Al-Shehbaz populations from the metallicolous soils located in Auby (North of France, AU population), Val del Riso (North of Italy, I16 population) and Bukowno (South of Poland, PL22 population) (Meyer et al., 2015) were grown in hydroponic conditions. The standard control medium (CM) was composed of $0.88 \mathrm{mM}$ $\mathrm{K}_{2} \mathrm{SO}_{4}, 2 \mathrm{mM} \mathrm{Ca}\left(\mathrm{NO}_{3}\right)_{2}, 1 \mathrm{mM} \mathrm{MgSO}{ }_{4}, 0.25 \mathrm{mM} \mathrm{KH}_{2} \mathrm{PO}_{4}, 10 \mu \mathrm{M}$ $\mathrm{H}_{3} \mathrm{BO}_{3}, 0.1 \mu \mathrm{M} \mathrm{CuSO}_{4}, 0.6 \mu \mathrm{M} \mathrm{MnSO}_{4}, 0.01 \mu \mathrm{M}\left(\mathrm{NH}_{4}\right)_{6} \mathrm{Mo}_{7} \mathrm{O}_{24}$, $10 \mu \mathrm{M} \mathrm{ZnSO}, 10 \mu \mathrm{M} \mathrm{NaCl}, 20 \mu \mathrm{M}$ Fe-EDTA and $0.25 \mathrm{mM}$ MES, $\mathrm{pH} 5.8$ (Meyer et al., 2015). Plants were grown at $21^{\circ} \mathrm{C}, 70 \%$ air humidity, under short day conditions ( $8 \mathrm{hr}$ of light per day) with a light intensity of $80 \mu \mathrm{mol}$ of photons $\mathrm{m}^{-2} \mathrm{~s}^{-1}$. After 4 weeks of growth, plants were maintained in $\mathrm{CM}$ or challenged with $0.2-5 \mu \mathrm{M} \mathrm{CdSO}_{4}$ in CM for 7-10 days. At the end of the treatment, roots and leaves were harvested separately from each individual, washed twice in distilled water, dried with absorbent paper, and frozen in liquid nitrogen.

\subsection{Protein extraction and immunoblotting}

Proteins from Arabidopsis tissues were extracted by grinding frozenpowdered tissues in $50 \mathrm{mM}$ Tris- $\mathrm{HCl}, \mathrm{pH} 8.0,10 \%$ (vol/vol) glycerol and protease inhibitors (Roche Applied Science). Samples were centrifuged at $16,000 \times g$ for $20 \mathrm{~min}$ and the supernatant used as a source of soluble proteins. Pellets were suspended in the extraction buffer supplemented with $2 \%$ (wt/vol) SDS, incubated for $15 \mathrm{~min}$ at room temperature, and centrifuged as before to recover solubilized membrane proteins. Proteins were resolved by SDS-polyacrylamide gel (SDS-PAGE), transferred to nitrocellulose membrane, and probed with an antibody against trimethyl-Lys (abcam 76118). Membranes were also probed with antibodies against fructose bisphosphate aldolase (Mininno et al., 2012) and the beta subunit of ATPase (Agrisera, ASO3 030) for the normalization of protein loading. Protein detection was achieved using the ECL Plus Western Blotting detection reagents.

\section{3 | Identification of Lys-methylated proteins by mass spectrometry}

Sample preparation - soluble proteins from root and leaf samples were resolved by SDS-PAGE and bands were cut in the range 25-30 kDa.
After washing with water and then $25 \mathrm{mM} \mathrm{NH}_{4} \mathrm{HCO}_{3}$ gel bands were destained twice with $1 \mathrm{ml}$ of $\mathrm{CH}_{3} \mathrm{CN}$ and dried at room temperature. Disulphide bridges were reduced using $10 \mathrm{mM}$ dithiothreitol at $56^{\circ} \mathrm{C}$ for $45 \mathrm{~min}$ and cysteine were alkylated using $55 \mathrm{mM}$ iodoacetamide for $30 \mathrm{~min}$ in darkness. Gel bands were washed twice with $50 \%$ (vol/vol) $\mathrm{CH}_{3} \mathrm{CN}$ in $25 \mathrm{mM} \mathrm{NH}_{4} \mathrm{HCO}_{3}$, then dehydrated with $\mathrm{CH}_{3} \mathrm{CN}$, and finally dried at room temperature. In-gel protein digestion was performed overnight at $37^{\circ} \mathrm{C}$ with trypsin (Sequencing Grade Modified Trypsin, Promega, Madison) at a final concentration of $0.005 \mu \mathrm{g} / \mu \mathrm{l}$. Peptides were extracted twice using $2 \%$ (vol/vol) formic acid in $80 \%$ (vol/vol) $\mathrm{CH}_{3} \mathrm{CN}$, dried, and then suspended in $20 \mu \mathrm{l}$ of $2 \%$ (vol/vol) formic acid before LC-MS/MS analysis.

Mass-spectrometry analysis - LC-MS/MS experiments were done using an UltiMate 3000 RSLCnano system interfaced online with a nano easy ion source and a Q Exactive Plus Orbitrap mass spectrometer (Thermo Fisher Scientific Inc., Waltham, MA) operating in a datadependent acquisition (DDA) mode. Peptides were separated by reverse-phase chromatography (PepMap C18, $2 \mu \mathrm{m}$ particle size, $100 \AA$ A pore size, $75 \mu \mathrm{m}$ i.d. $\times 50 \mathrm{~cm}$ length, Thermo Fisher Scientific) at a flow rate of $300 \mathrm{nl} / \mathrm{min}$. Loading buffer (Solvent $\mathrm{A}$ ) was $0.1 \%$ ( $\mathrm{vol} / \mathrm{vol}$ ) trifluoroacetic acid in water and elution buffer (Solvent B) was $0.1 \%$ ( $\mathrm{vol} / \mathrm{vol}$ ) trifluoroacetic acid in $80 \%$ (vol/vol) acetonitrile. The three-step gradient employed was $4-25 \%$ of Solvent B in $103 \mathrm{~min}$, then $25-40 \%$ of Solvent B from 103 to $123 \mathrm{~min}$, finally 40-90\% of Solvent B from 123 to 125 min. Peptides were transferred to the gaseous phase with positive ion electrospray ionization at $1.7 \mathrm{kV}$. In DDA, the top 10 precursors were acquired between 375 and $1,500 \mathrm{~m} / \mathrm{z}$ with a 2 Thomson selection window, dynamic exclusion of $40 \mathrm{~s}$, normalized collision energy of 27 and resolutions of 70,000 for MS and 17,500 for MS2. Spectra were recorded with the Xcalibur software (4.0.27.19) (Thermo Fisher Scientific).

Identification of methylpeptides - Mass spectrometry data were processed using the Proteome Discoverer software (version 1.4.0.288, Thermo Fisher Scientific) and a local search engine (Mascot, version 2.4.1, Matrix Science). Data from A. thaliana samples were searched against the TAIR (2011) non-redundant database containing 35,387 sequences with the following parameters: trypsin as enzyme, 3 missed cleavages allowed, carbamidomethylation of cysteine as a fixed modification, and mono-, di-, tri-methylation of Lys, acetylation of Lys, N-terminal acetylation of the protein, deamidation of asparagine and glutamine, $\mathrm{N}$-terminal pyromutamylation of glutamine and glutamate, and oxidation of methionine as variable modifications. Mass tolerance was set at $10 \mathrm{ppm}$ on full scans and 0.02 Da for fragment ions. Proteins were validated once they contained at least two peptides with a $p$-value <.05. Two additional filters were used to improve the identification of trimethylated Lys peptides: 1/selection of peptides with Mascot score $\geq 30,2$ /discrimination of Lys trimethylation (mass shift of 42.04695 ) and Lys acetylation (mass shift of 42.01056 ) using a mass tolerance at $2 \mathrm{ppm}$. Ambiguous peptides were eliminated and spectra of interest were checked manually to confirm their sequence and the nature of modifications. Similar parameters were used to identify trimethylated Lys peptides in samples from A. halleri and A. lyrata but MS data were searched using a 
local database built using the $A$. lyrata genome resources (Alyrata_384_v2.1 from the Joint Genome Institute) (Hu et al., 2011; Rawat et al., 2015).

\section{4 | Screening of $A$. thaliana mutants in protein Lys methyltransferase genes}

Seeds of the T-DNA insertion lines in 23 KMT genes were obtained from the European Nottingham Arabidopsis Stock Centre. Mutants were genotyped by PCR using gene- and T-DNA-specific primers (Table S1). Amplicons were sequenced to map the insertion sites.

Seeds of Col-0 and homozygous KMT mutants were surface sterilized and sown onto Petri dishes containing half-strength Murashige and Skoog (MS/2) medium with $0.8 \%$ (wt/vol) agar. After 2 days of stratification at $4^{\circ} \mathrm{C}$, plates were transferred to a growth chamber for 4 days $\left(21^{\circ} \mathrm{C}, 70 \%\right.$ air humidity, $18 \mathrm{hr}$ of light per day, $80 \mu \mathrm{mol}$ of photons $\mathrm{m}^{-2} \mathrm{~s}^{-1}$ ). Twenty seedlings per genotype were then transferred to square Petri dishes containing either $\mathrm{MS} / 2$ medium or $\mathrm{MS} / 2$ medium with $20 \mu \mathrm{M} \mathrm{CdSO}$. Plates were oriented vertically in the growth chamber and scanned (GS-800 scanner, BioRad) after 0, 3, 6,8 and 10 days of treatment. The root length of each seedling was measured with the ImageJ software. Root length at Day 8 and root elongation rate (in $\mathrm{cm} \mathrm{day}^{-1}$ ) between Days 3 and 8 were used as primary criteria to monitor the inhibitory effect of $\mathrm{Cd}$. Also, the tolerance index ( $\mathrm{TI}$ ) to $\mathrm{Cd}$ was calculated for each line by dividing the primary parameter (length or elongation rate) measured in the presence of $\mathrm{Cd}$ by the one measured in the control condition. One hundred TI were calculated for each line by random sampling of one value in the $\mathrm{Cd}$ and control conditions, respectively, with replacement at each draw.

\subsection{Gene expression data mining}

The expression of genes coding KMTs in A. thaliana seedlings challenged with $\mathrm{Cd}$ was analysed using data from the literature. First, we used our genome-wide CATMA microarray analysis of roots and shoots from 4-week-old $A$. thaliana plants exposed to 5 or $50 \mu \mathrm{M} \mathrm{Cd}$ for 2, 6 or $30 \mathrm{hr}$ (GSE10675) (Herbette et al., 2006). Next, we collected four datasets from the Gene Expression Omnibus database. They correspond to (a) 2-week-old seedlings grown in MS/2 agar plates and treated with $70 \mu \mathrm{M}$ Cd for 2 hours (GSE90701) (Khare et al., 2017); (b) roots from 5-week-old plants grown in hydroponics and treated for 7 days with $1 \mu \mathrm{M}$ Cd (GSE94314) (Fischer, Spielau, \& Clemens, 2017); (c) roots from 3-week-old seedlings grown in hydroponics and challenged with $200 \mu \mathrm{M}$ Cd for $6 \mathrm{hr}$ (GSE22114) (Li et al., 2010) and (4) 7-day-old seedlings grown in MS/2 agar plates and treated for $6 \mathrm{hr}$ with $200 \mu \mathrm{M} \mathrm{Cd}$ (GSE35869) (Jobe et al., 2012). Also, we analysed curated data from the comparative transcriptomic analysis of $A$. thaliana and A. halleri plants challenged with $10 \mu \mathrm{M}$ or $25 \mu \mathrm{M}$ $\mathrm{Cd}$, respectively, in hydroponics for $2 \mathrm{hr}$ (Weber, Trampczynska, \& Clemens, 2006). Relative expression levels of KMT genes were retrieved from the different experiments, the ratio between $\mathrm{Cd}$ and control conditions were calculated from pairwise comparisons, and a non-parametric Student's $t$ test was performed on log2 ratio to determine differentially expressed genes (DEGs, with $p$-value <.05) and the threshold was set at twofold $(-1 \leq \log 2$ fold change $\geq 1)$. Finally, we used the RNA-seq data we obtained to analyse the tolerance strategies to $\mathrm{Cd}$ of two metallicolous populations of $\mathrm{A}$. halleri (BioProject PRJNA388549) (Corso et al., 2018). In this experiment, gene expression in the 116 and PL22 populations was analysed after 10 days of treatment with $5 \mu \mathrm{M} \mathrm{Cd}$ in hydroponics. For the identification of DEGs, we selected genes with more than 10 read counts in any of the triplicate, applied a non-parametric $t$ test ( $p$-value $<0.05$ ) in pairwise comparisons, and used a 1.4-fold change threshold value $(-0.5 \leq \log 2$ fold change $\geq 0.5$ ).

\subsection{Determination of Cd by inductively coupled plasma mass spectrometry}

Plant samples were dehydrated at $90^{\circ} \mathrm{C}$, weighed for data normalization, and digested at $90^{\circ} \mathrm{C}$ for $4 \mathrm{hr}$ in $65 \%$ (wt/wt) ultrapure $\mathrm{HNO}_{3}$. Mineralized samples were diluted in $0.5 \%$ (vol/vol) $\mathrm{HNO}_{3}$ and analysed using an iCAP RQ quadrupole mass instrument (Thermo Fisher Scientific GmbH, Germany). ${ }^{111}$ Cadmium concentration was determined using a standard curve and corrected using an internal standard solution of ${ }^{103}$ Rhodium added online.

\section{7 | Statistical analysis}

Non-parametric statistical analysis was performed on our datasets, which typically contain small sample sizes $(n \leq 20)$ and do not meet the assumptions of parametric tests (normal distribution and homogeneity of variance, as determined using the Shapiro-Wilk and Fisher tests, respectively). Multiple non-parametric comparisons were performed with the Dunnett's many-to-one test using the nparcomp package (Konietschke, Placzek, Schaarschmidt, \& Hothorn, 2015) and the $\mathrm{R}$ computing environment. The Fischer's approximation method was used and the confidence level was set at $95 \%$.

\section{$3 \mid$ RESULTS}

\subsection{Analysis of the patterns of Lys-methylated proteins in sensitive and tolerant Arabidopsis species exposed to $\mathrm{Cd}$}

We analysed the effect of Cd stress on the pattern of Lys-methylated proteins in roots and leaves of three Arabidopsis species showing contrasting $\mathrm{Cd}$ tolerance and accumulation. The analysis was done by immunoblotting and focused on Lys trimethylation on proteins other than histones because antibodies against mono- and dimethyl-Lys are less sensitive and specific than anti trimethyl-Lys antibodies (Alban et al., 2014). Moreover, the procedure used for protein isolation was 
not appropriate for the extraction of histones, which requires acidic or high salt conditions (Shechter, Dormann, Allis, \& Hake, 2007). We used the $\mathrm{Cd}$-sensitive species $\mathrm{A}$. thaliana (ecotype Columbia, Col-0) and A. lyrata ssp. petraea, and the A. halleri species (Auby [AU] population) that displays $\mathrm{Cd}$ hypertolerance and hyperaccumulation traits (Meyer et al., 2015). Plants were grown hydroponically for 5 weeks in a standard culture medium and then challenged with $5 \mu \mathrm{M} \mathrm{CdSO}_{4}$ for 9 days. In these conditions, the symptoms of $\mathrm{Cd}$ toxicity (growth inhibition, chlorosis and inhibition of photosynthesis) were visible for $A$. thaliana and A. lyrata plants, but not for A. halleri (Figure S1). The patterns of Lys trimethylated proteins were complex with many polypeptides detected in root extracts and in leaf soluble extracts (Figure 1), illustrating the wide array of targets of Lys methylation. The analysis was less informative for leaf membrane proteins with only a few and diffuse bands detected. A careful examination of the trimethyl-Lys signals indicated several changes in the expression patterns of methylated proteins between species or between control and Cd-treated plants (Figure 1). For example, a Lys-trimethylated protein of $43-45 \mathrm{kDa}$ was strongly labelled in A. lyrata leaf soluble extracts, regardless of growth conditions, but was not detectable in A. thaliana and A. halleri extracts. The most obvious example regarding the effect of $\mathrm{Cd}$ was a doublet of proteins at about $26-28 \mathrm{kDa}$ in leaf soluble extracts. This doublet was constitutive in $A$. halleri, that is, present in both culture conditions, detected in A. lyrata treated with Cd, but not observed in A. lyrata in control conditions nor in $A$. thaliana with or without $\mathrm{Cd}$ treatment (Figure 1a). Noteworthy, a doublet of proteins with a similar migration behaviour was detected with a strong and constant immunostaining in root soluble extracts from the three Arabidopsis species in both culture conditions (Figure 1c). Similar western blot analyses were performed with two other populations of A. halleri, I16 and PL22, that are hypertolerant to Cd (Meyer et al., 2015). The patterns of Lys-trimethylated proteins in 116 and PL22 were similar to those observed for AU, and notably the doublet of proteins at $26-28 \mathrm{kDa}$ in leaf soluble extracts was detected in control and stress conditions (Figure S2). Together, these results indicate that $\mathrm{Cd}$ triggers changes in the steady-state level of some Lys-methylated proteins, with contrasting patterns depending on the Arabidopsis species and possibly their ability to tolerate and accumulate $\mathrm{Cd}$.

\section{2 | Identification of Lys-methylated proteins related to Cd stress in Arabidopsis}

We used protein tandem mass spectrometry (MS/MS) to identify Lysmethylated proteins whose expression is modulated by $\mathrm{Cd}$. The identification of Lys-methylated peptides by MS/MS is still challenging for many reasons (Wang, Wang, \& Ye, 2017), including the low abundance and/or low methylation level of targets and the high false discovery rates for methylpeptides identification due to amino acid substitutions that are isobaric with methylation events (Hart-Smith, Yagoub, Tay, Pickford, \& Wilkins, 2016; Ong, Mittler, \& Mann, 2004). To address this challenge, we focused on the identification of the abundant doublet of trimethylated proteins at 26-28 kDa for which (a)

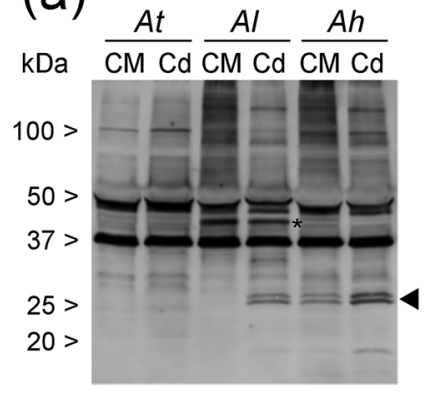

(b)

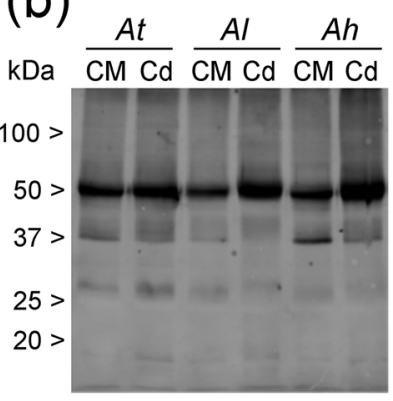

FBA $>$

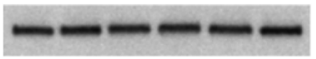

ATPB $>$

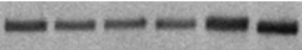

(c)

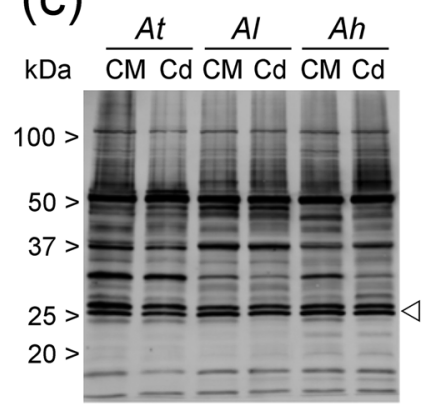

(d)

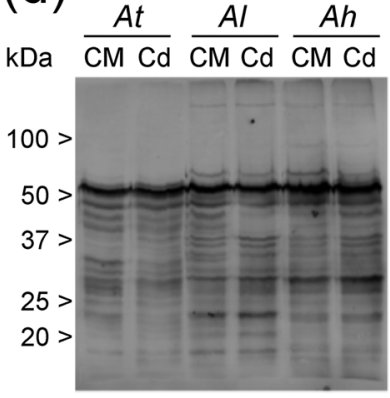

$\mathrm{FBA}>$

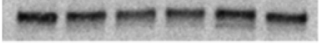

ATPB $>$

FIGURE 1 Immunodetection of Lys-trimethylated proteins in roots and leaves from Arabidopsis plants challenged with Cd. Plants grown in hydropony were maintained in control medium (CM) or challenged with $5 \mu \mathrm{M} \mathrm{CdSO}_{4}$ for 9 days. Soluble and membrane proteins ( $30 \mu \mathrm{g}$ per lane) from root and leaf tissues were analysed by western blot using antibodies specific to trimethyl-Lys (ab76118, abcam). (a) Leaf soluble proteins. (b) Leaf membrane proteins. (c) Root soluble proteins. (d) Root membrane proteins. The asterisk indicates a protein that is labelled specifically in leaf soluble extracts from A. lyrata. The triangles indicate protein doublets at 26-28 kDa that is methylated in all root samples $(\triangleleft)$ and follows a species- and/or condition-dependent immunolabeling in leaves ( $)$. At, A. thaliana; $\mathrm{Al}$, A. lyrata Ah, A. halleri (AU population). Hybridizations with antibodies against fructose 1,6-bisphosphate aldolase (FBA) and the beta subunit of ATPase (ATPB) have been used as loading controls for soluble and membrane fractions, respectively

the expression pattern was potentially interesting regarding $\mathrm{Cd}$ stress (Figure 1). We used a filtering procedure adapted from Alban et al. (2014) to identify Lys-trimethylated peptides with high confidence. Also, MS/MS data from A. lyrata and A. halleri were searched against a database built from the $A$. lyrata genome, and not against the A. thaliana genome, to improve the identification of Lys-methylated peptides. Using this procedure, we were able to identify Lystrimethylated peptides belonging to nine proteins in the gel bands of interest in the range 25-30 kDa (Table 1, Table S2 and Figure S3).

In root samples, where two protein bands at 26-28 kDa were strongly labelled with the trimethyl-Lys antibodies in all species and conditions (Figure 1c), we identified Lys-trimethylated peptides belonging to the Eukaryotic Elongation factor $1 \mathrm{~A}$ (EEF1A), the 


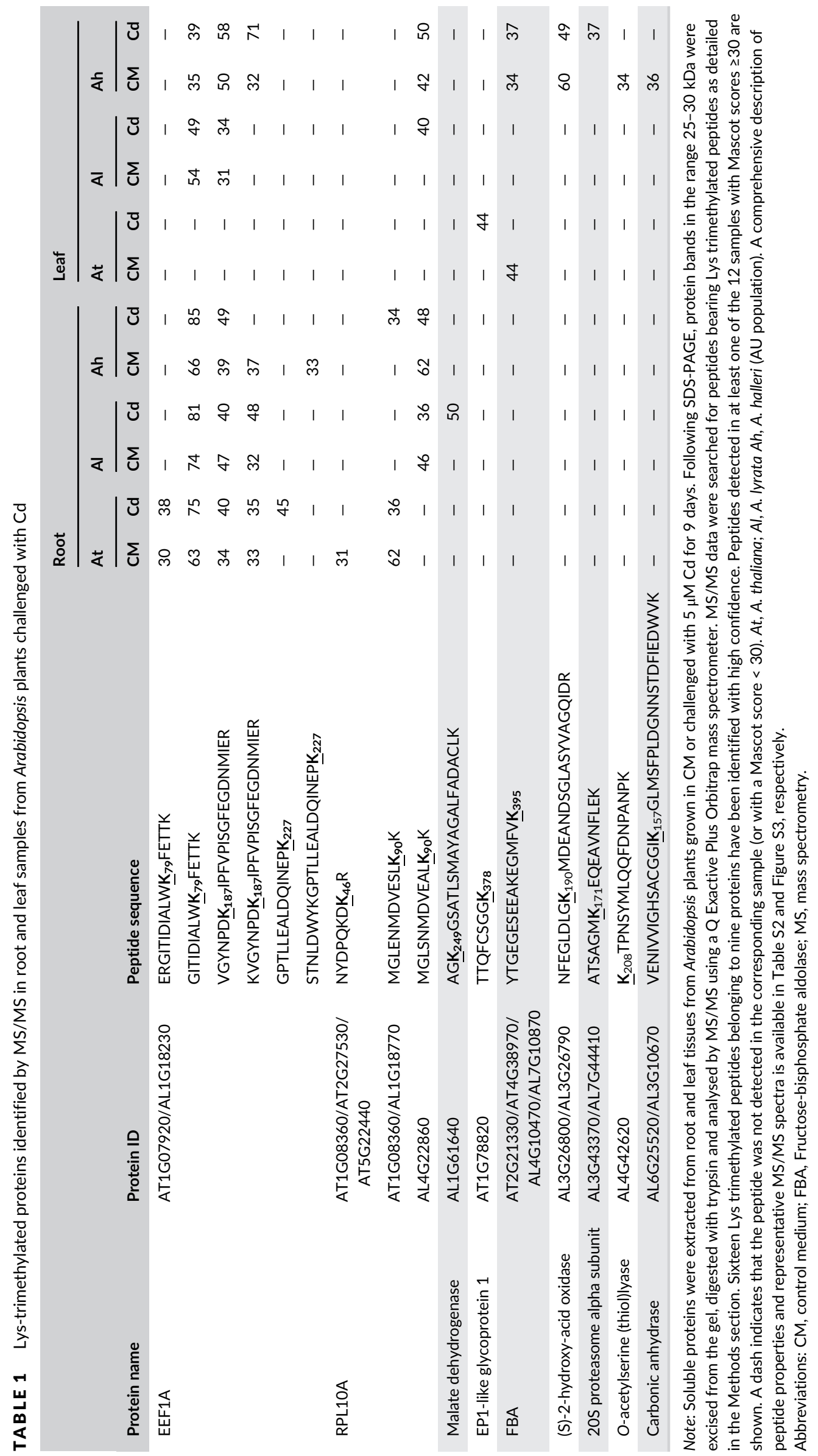


ribosomal protein L10 (RPL10A), and a malate dehydrogenase. For malate dehydrogenase, the peptide bearing the previously unknown trimethylated Lys249 was detected only in the extract from A. lyrata plants treated with $\mathrm{Cd}$ (Table 1). For EEF1A, we identified three Lys trimethylation sites, two of them (Lys79 and Lys187) were detected in the three Arabidopsis species and were already known in several plant species (Alban et al., 2014; Lopez-Valenzuela, Gibbon, Hughes, Dreher, \& Larkins, 2003; Ndamukong, Lapko, Cerny, \& Avramova, 2011) while the third one (Lys227) was only detected in A. thaliana and was previously unknown. For RPL10A, two Lys trimethylation sites were identified, the first (Lys90) was formerly identified in A. thaliana (Carroll, Heazlewood, Ito, \& Millar, 2008) while the second (Lys46) was not known. The identification of known methylation sites in EEF1A and RPL10A validated the overall pipeline for methylpeptide search and the use of the A. lyrata genome for MS/MS spectra assignation in both $A$. lyrata and $A$. halleri.

In leaf samples, where the immunodetection of the doublet of Lys-methylated proteins is species and condition dependent (Figure 1a), we identified trimethylated Lys residues in EEF1A, RPL10A and six additional proteins (Table 1). Methylation of chloroplastic fructose 1,6-bisphosphate aldolases at a specific Lys residue (Lys395) was reported earlier (Alban et al., 2014; Ma et al., 2016; Mininno et al., 2012), while the other proteins were not previously known to be methylated.

We compared western blot and MS/MS analyses to try to assign the major trimethylated proteins at 26-28 kDa. The detection pattern of peptides from RPL10A bearing a trimethylated Lys90 in root and leaf samples (Table 1) matched exactly the signals obtained with the antibodies against trimethyl-Lys (Figure 1a). For EEF1A, the overlap between methylpeptides and immunoblotting signals was also important. However, EEF1A is a very abundant cytosolic protein of about $50 \mathrm{kDa}$ (Figure S4), suggesting that its identification in bands of 25-30 kDa was due to the high sensitivity of MS/MS detection and presumably protein smearing. Although the approach we used did not provide quantitative information about the identified methylpeptides, these results suggest that RPL10A ( $25 \mathrm{kDa}$ ) could contribute to one of the two intense signals observed by western blot. Despite the use of a high sensitive mass spectrometer and a robust identification pipeline, we have reached the limits of our approach and were not able to identify the second Lys-trimethylated protein, presumably abundant and interesting regarding $\mathrm{Cd}$ stress. Because of this technical bottleneck to investigate further the role of Lys-methylated proteins during metal stress, we moved on to the analysis of KMTs, the main drivers in the dynamics of protein Lys methylation.

\subsection{Expression of $A$. thaliana genes coding protein Lys methyltransferases in response to $\mathrm{Cd}$}

In A. thaliana, 48 genes coding KMTs from the SDG have been identified (Serre et al., 2018). Only two KMTs belonging to the SBS superfamily have been characterized yet in plants, namely, the cytosolic enzyme CaMKMT that methylates calmodulin (CaM) (Banerjee et al.,
2013) and the PrmA methyltransferase that modifies ribosomal protein L11 in plastids and mitochondria (Mazzoleni et al., 2015). Using BLAST searches, we identified 11 genes from $A$. thaliana that are orthologous to bacterial, yeast and human KMTs with a SBS structural fold (Figure S5) (Le S.Q. \& Gascuel O. 2008; Tamura K., Stecher G., Peterson D., Filipski A. \& Kumar S. 2013). Thus, as a whole, the set of genes coding putative KMTs in A. thaliana comprised 59 members, with 48 SDG genes and 11 SBS genes.

In order to determine whether $\mathrm{Cd}$ could regulate the expression of KMT genes in A. thaliana, we analysed transcriptomic datasets from published works (Fischer et al., 2017; Herbette et al., 2006; Jobe et al., 2012; Khare et al., 2017; Li et al., 2010; Weber et al., 2006). These datasets correspond to different conditions of stress with variations in Cd concentration (1-200 $\mu \mathrm{M}$ ), treatment duration ( $2 \mathrm{hr}$ to 7 days), growth medium (agar plates or hydroponics), and stage of development (7-day-old seedlings to 5-week-old mature plants). The coverage of KMT genes was important in each of the microarray experiments (51-59 genes identified out of 59). We found that the expression of some KMT genes was regulated by $\mathrm{Cd}$ (Table S3). Most of the DEGs were found in an experiment with drastic conditions of stress ( $200 \mu \mathrm{M} \mathrm{Cd}$ for $6 \mathrm{hr}$ in hydroponics) (Li et al., 2010). In these conditions, $\mathrm{Cd}$ triggered the upregulation of 12 genes and the downregulation of three genes in roots (Table S3). Among these genes, only SBS7 was differentially regulated at a lower Cd concentration. Also, the expression of SDG29 was upregulated following a short-term exposure to $\mathrm{Cd}$. Together, these data indicate that the expression of a limited number of KMT genes is influenced by $\mathrm{Cd}$ in $\mathrm{A}$. thaliana.

\subsection{Expression of genes coding protein Lys methyltransferases in A. halleri populations with different properties of $\mathrm{Cd}$ accumulation}

To analyse whether $\mathrm{Cd}$ could modify the expression of genes coding KMTs in the Cd-tolerant species $A$. halleri we first used the comparative transcriptomic analysis from Weber et al. (2006). In this study, in which $A$. halleri plants from the population Langelsheim (Germany) were challenged with 25 or $125 \mu \mathrm{M} \mathrm{Cd}$ in hydroponic conditions for a short period (2 hr), none of the KMT genes was differentially expressed. Then, the expression of KMT genes was analysed in the 116 and PL22 populations challenged with Cd. After 4 weeks of acclimatization in hydroponic growth medium, plants were treated with $5 \mu \mathrm{M} \mathrm{CdSO}_{4}$ for 10 days and transcriptomic analysis was performed in root and shoot samples using RNA sequencing (Corso et al., 2018). Genes coding KMTs were retrieved from the RNAseq data and their expression was analysed. A principal component analysis (PCA) showed that the factor having the strongest impact on the expression profiles of KMT genes is the genetic unit (PL22 vs. I16), accounting for 52 and $65 \%$ of the variance in roots and shoots, respectively (Figure 2a). The effect of the treatment (Cd vs. CM) was less important, accounting for 34 and $19 \%$ of the variance in roots and shoots, respectively (Figure 2a). DEGs were then identified in two pairwise comparisons to estimate the effect of the genetic unit and the 
treatment ( $p<.05$, threshold set at 1.4-fold change) (Corso et al., 2018). In agreement with the PCA, the PL22/I16 comparison identified 16 DEGs in roots and 10 DEGs in shoots (Figure $2 b$ ), whereas the $\mathrm{Cd} /$ control comparison yielded only four DEGs in PL22 and none in I16 (Figure 2c). In PL22, three genes were induced by $\mathrm{Cd}$ in roots
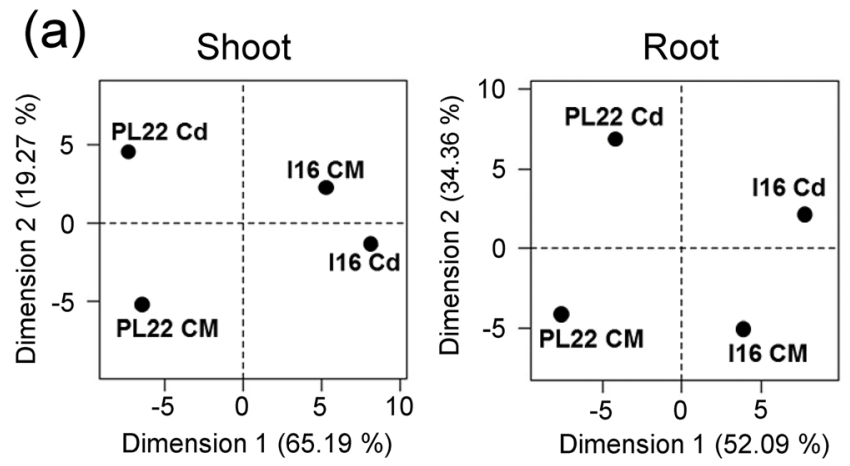

(b)

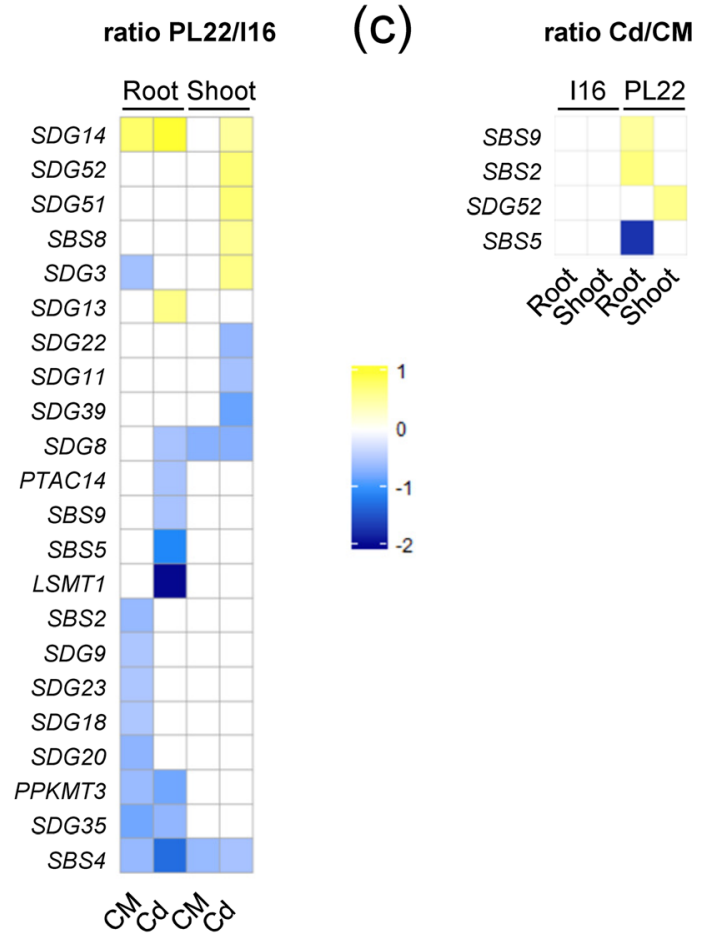

FIGURE 2 Expression of genes coding KMTs in the PL22 and I16 metallicolous populations of $A$. halleri challenged with $\mathrm{Cd}$. RNAseq analysis was performed using root and shoot samples from plants exposed to $5 \mu \mathrm{M} \mathrm{CdSO}_{4}$ for 10 days (Corso et al., 2018). (a) Principal component analysis of KMT genes expression in roots and shoots. (b) Differentially expressed KMT genes according to the genetic unit (PL22 vs. 116). The ratio between the steady-state expression level of each KMT gene in PL22 over I16 was calculated in all conditions (root $\pm \mathrm{Cd}$, shoot $\pm \mathrm{Cd}$ ) and differentially expressed genes

(DEGs) were selected using a log2 fold-change $\geq 0.5$ or $\leq-0.5$.

(c) Differentially expressed KMT genes according to the Cd treatment (Cd vs. control). The ratio between the steady-state expression level of each KMT gene in Cd-treated over untreated plants was calculated in all conditions (root and shoot from I16 and PL22) and DEGs were selected using a log2 fold-change $\geq 0.5$ or $\leq-0.5$. CM, control medium; $\mathrm{Cd}$, medium containing $5 \mu \mathrm{M} \mathrm{CdSO}_{4}$
(SBS2 and SBS9) or in shoots (SDG52), and the SBS5 gene was downregulated by $\mathrm{Cd}$ in roots. The four genes regulated by $\mathrm{Cd}$ are predicted to code for KMTs modifying non-histone substrates (Serre et al., 2018), suggesting that these methylation events could be related to the tolerance and/or accumulation properties of the metallicolous PL22 population.

\section{5 | Identification of protein Lys methyltransferase mutants from $A$. thaliana with altered tolerance to $\mathrm{Cd}$}

We used a screening procedure with knockout mutants to determine whether some KMT genes could play a role in the response of A. thaliana to $\mathrm{Cd}$. We included only genes coding for KMTs modifying, or predicted to modify, non-histone substrates (Serre et al., 2018). Our selection comprised all genes (11) coding SBS enzymes and 15 genes coding SDG enzymes from Classes VI and VII. SDG enzymes from Classes I to $V$ are known to methylate histones and some of them also accept non-histone substrates (Serre et al., 2018). Genes coding these enzymes were not included in our analysis since mutations in KMTs acting on histones, or on histones plus non-histone substrates, can lead to pleiotropic effects (e.g., Ndamukong et al., 2011), thus complicating the interpretation of the screening results. We obtained homozygous T-DNA insertion lines disrupting 23 of the selected genes (Table S1). Three genes could not be retained for the screening, of which PAP7 for which the mutation is lethal in photoautotrophic conditions (Grubler et al., 2017).

We analysed mutant seedlings for root growth inhibition by $\mathrm{Cd}$, which is a simple and efficient method to assess tolerance to a toxic element (Remy \& Duque, 2016). The procedure was set up using Col0 seedlings and the cad2.1 null mutant that is hypersensitive to $\mathrm{Cd}$ (Howden, Andersen, Goldsbrough, \& Cobbett, 1995). In brief, 4-dayold seedlings were transferred to MS/2 medium supplemented or not with $20 \mu \mathrm{M} \mathrm{CdSO}_{4}$ and grown vertically for another 10 days in photoautotrophic conditions (no source of reduced carbon added to the medium) (Figure 3). Root length at Day 8 and root elongation rate between Days 3 and 8 were used as primary criteria to assess tolerance of the mutant lines to $\mathrm{Cd}$ (Figure 3). To address line-dependent differences in root growth that could interfere with the interpretation of the screening we also calculated the TI for the two primary parameters, which corresponds to the ratio between the values in $\mathrm{Cd}$ containing over CM (Metwally, Safronova, Belimov, \& Dietz, 2005) (Figure 3). The concentration of $\mathrm{Cd}$ in the medium $(20 \mu \mathrm{M})$ was selected to produce a significant root growth inhibition ( $\mathrm{TI}$ about 0.5 ) and to allow the identification of insertion lines that are either more tolerant or more sensitive to $\mathrm{Cd}$ than $\mathrm{Col}-\mathrm{O}$ in our experimental conditions.

The results of the screening procedure have been summarized in a heatmap displayed in Figure 4. Mutants were clustered in three mains categories. First, the calculated Tls for 14 insertion lines were comparable with the Col-0 ecotype. Second, five mutants (sdg51, 
(a)
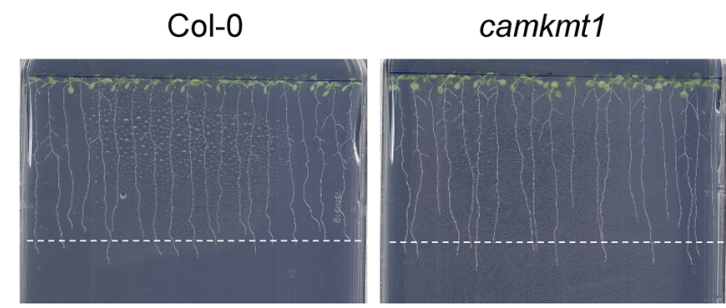

Cd
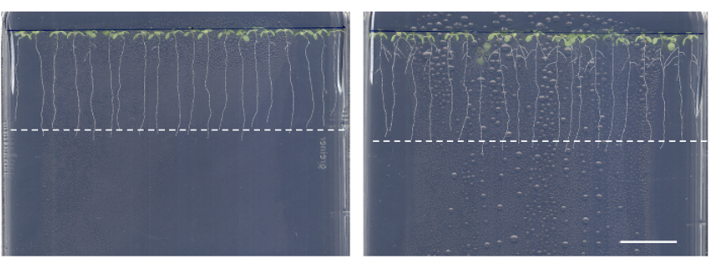

(b)
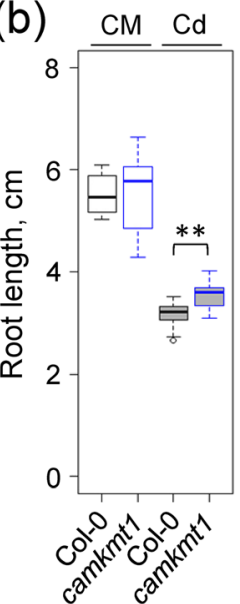

(c)

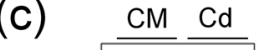

(d)
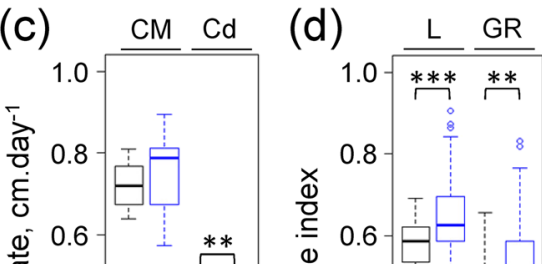

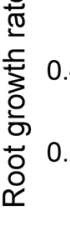

$-$

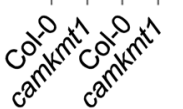

\begin{tabular}{|c|c|c|c|c|c|c|c|}
\hline \multirow[b]{2}{*}{ sdg52 } & \multicolumn{2}{|c|}{$\mathrm{CM}$} & \multicolumn{2}{|c|}{$\mathrm{Cd}$} & \multicolumn{2}{|c|}{ Tol index } & \\
\hline & 1.18 & 1.16 & 1.31 & 1.47 & 1.10 & 1.24 & \\
\hline camkmt1 & 1.01 & 1.04 & 1.12 & 1.15 & 1.14 & 1.11 & \\
\hline sdg51 & 0.89 & 0.83 & 1.02 & 1.05 & 1.14 & 1.27 & \\
\hline sbs7 & 0.85 & 0.82 & 0.97 & 1.07 & 1.16 & 1.30 & \\
\hline sbs9 & 0.88 & 0.88 & 1.05 & 1.07 & 1.26 & 1.15 & \\
\hline$s d g 42$ & 0.88 & 0.97 & 0.86 & 0.87 & 1.04 & 0.98 & \\
\hline sbs 3 & 0.97 & 0.95 & 1.03 & 1.07 & 1.03 & 1.09 & \\
\hline sdg38 & 0.96 & 0.96 & 0.88 & 0.86 & 0.92 & 0.98 & \\
\hline sdg36 & 1.11 & 1.12 & 0.93 & 0.94 & 0.93 & 0.85 & \\
\hline prma & 0.88 & 0.94 & 1.09 & 0.92 & 0.97 & 1.04 & \\
\hline sdg40 & 0.93 & 0.94 & 0.92 & 0.94 & 0.98 & 1.03 & \\
\hline sbs5 & 0.88 & 0.93 & 1.00 & 1.09 & 1.12 & 1.10 & \\
\hline ppkmt1 & 0.86 & 0.87 & 0.87 & 0.97 & 1.05 & 0.98 & \\
\hline ppkmt2 & 0.84 & 0.91 & 0.93 & 1.12 & 1.08 & 1.14 & \\
\hline ppkmt3 & 0.66 & 0.53 & 0.66 & 0.76 & 1.06 & 1.12 & \\
\hline Ismt1 & 0.79 & 0.81 & 0.65 & 0.78 & 0.99 & 0.98 & \\
\hline sdg39 & 0.81 & 0.83 & 0.91 & 1.01 & 1.14 & 1.06 & \\
\hline$s d g 35$ & 0.88 & 0.91 & 0.94 & 0.99 & 1.07 & 1.05 & \\
\hline sbs1 & 0.79 & 0.83 & 0.90 & 0.89 & 1.00 & 1.04 & \\
\hline$s d g 50$ & 1.19 & 1.37 & 1.01 & 0.94 & 0.75 & 0.72 & \\
\hline sbs 6 & 1.15 & 1.20 & 1.03 & 0.99 & 0.87 & 0.81 & \\
\hline sbs 8 & 1.14 & 1.15 & 1.14 & 0.90 & 0.85 & 0.76 & \\
\hline sbs2 & 0.94 & 0.86 & 0.79 & 0.79 & 0.77 & 0.77 & \\
\hline
\end{tabular}

FIGURE 4 Heatmap summarizing the screening of KMT mutants from $A$. thaliana for their tolerance to $\mathrm{Cd}$. Each line identifies a KMT insertion line, each column defines the primary parameters of the screening procedure (root length at Day 8 and root growth rate (GR) from Day 3 to 8 in control and Cd-containing medium) and the calculated tolerance indices (ratio $\mathrm{Cd} / \mathrm{CM}$ ). For each parameters, statistical analysis indicated whether a KMT mutant was similar (white box), lower (blue box) or higher (yellow box) than the wild-type ecotype Col-0. Values indicate the ratio between the mutant and Col-0 [Colour figure can be viewed at wileyonlinelibrary.com]

\subsection{Characterization of a Cd-tolerant mutant deficient in calmodulin Lys methyltransferase}

Two mutants identified in the screening were selected for further investigations. The first insertion line, camkmt1, was found more tolerant to $\mathrm{Cd}$ than the wild type (Figure 4) and is inactivated in the CAMKMT gene coding the CaM Lys methyltransferase (Banerjee et al., 2013). A previous analysis of the camkmt1 null-mutant showed that disruption of the CAMKMT gene abolished CaM methylation at Lys315 and revealed a link between the methylation status of CaM is part of the responses used by $A$. thaliana to cope with $\mathrm{Cd}$ stress. 
and seedling tolerance to salt, heat and cold stress (Banerjee et al., 2013).

The tolerance to $\mathrm{Cd}$ of the camkmt1 knockout line was verified using root growth assays and seedling biomass measurements using variable concentrations of the toxic metal (from 5 to $20 \mu \mathrm{M}$ ). For root elongation inhibition, the improved tolerance of camkmt1 was significant only at the highest $\mathrm{Cd}$ concentration (Figure 5a). For seedling growth inhibition, the inhibitory effect of $\mathrm{Cd}$ on biomass was significantly less important for camkmt 1 than for the wild type at 10 and $20 \mu \mathrm{M} \mathrm{Cd}$ (Figure 5b). CaMKMT is involved in the methylation of the major calcium (Ca) sensor CaM (Banerjee et al., 2013) and Ca is known to alleviate Cd toxicity (Baliardini, Meyer, Salis, Saumitou-Laprade, \& Verbruggen, 2015; Suzuki, 2005). Consequently, the tolerance of camkmt1 was analysed using a fixed concentration of $\mathrm{Cd}(20 \mu \mathrm{M})$ and fluctuating concentrations of $\mathrm{Ca}(0.5,1$ and $1.5 \mathrm{mM})$. Changes in $\mathrm{Ca}$ availability did not modify the growth of seedlings in the absence of $\mathrm{Cd}$ (Figure 6). The inhibition of root elongation and seedling biomass by $\mathrm{Cd}$ was inversely correlated to $\mathrm{Ca}$ concentration in the medium. Also, the camkmt1 line was found significantly more tolerant to $\mathrm{Cd}$ than the wild type at each Ca concentration tested (Figure 6). Together, these data validated our screening approach and confirmed the identification of a $\mathrm{Cd}$-tolerant $\mathrm{A}$. thaliana mutant affected in the methylation of CaM.

Then, we used inductively coupled plasma mass spectrometry (ICP-MS) to determine whether the difference in Cd-tolerance of (a)

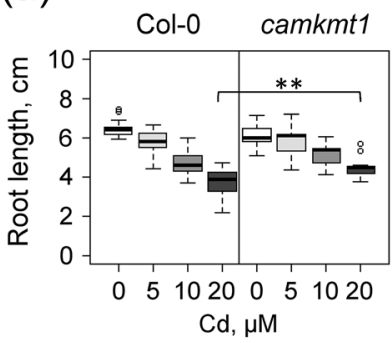

(c)

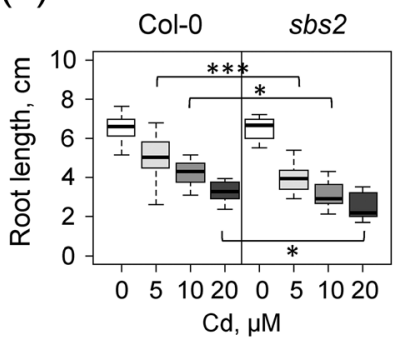

(b)

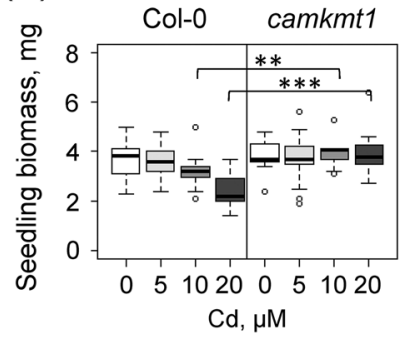

(d)

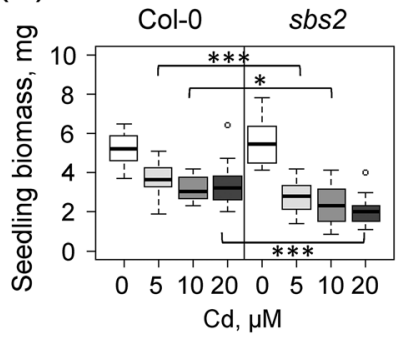

FIGURE 5 Tolerance to Cd of the protein Lys methyltransferases camkmt 1 and sbs 2 mutants. Four-day-old seedlings were transferred onto $\mathrm{MS} / 2$ medium containing various amount of $\mathrm{CdSO}_{4}$ and grown vertically for 10 days in photoautotrophic conditions. (a,c) Dosedependent inhibition of root growth by $\mathrm{Cd}$. Root length was measured at Day 8. (b,d) Dose-dependent inhibition of seedling biomass by $\mathrm{Cd}$. Seedling fresh weight was measured at Day 10. Each distribution represents $n=20$ seedlings. Statistical significance determined using a non-parametric Dunnett's test is shown, with $p<.05(*), p<.01\left(^{* *}\right)$ and $p<.001(* * *)$ camkmt1 could be due to changes in its capacity to take up the element from the environment. Cadmium was measured in roots and shoots of plants grown in hydroponics and challenged with various $\mathrm{Cd}$ concentrations $(0.2,1$ and $5 \mu \mathrm{M})$ for 7 days. There was no significant difference in the absorption and translocation of $\mathrm{Cd}$ in camkmt1 as compared to Col-0 (Figure S6). Thus, the tolerance to Cd of camkmt1 was not due to changes in $\mathrm{Cd}$ accumulation but rather to an improved capacity to cope with the toxic element.

\section{7 | Characterization of a Cd-sensitive mutant affected in the protein Lys methyltransferase SBS2}

The sbs2 line was selected for further investigations because it is more sensitive to $\mathrm{Cd}$ (Figure 4) and the SBS2 gene is upregulated in the roots of the $A$. halleri PL22 population challenged with $\mathrm{Cd}$ (Figure 2c). Yet, the function of the SBS2 gene is unknown.
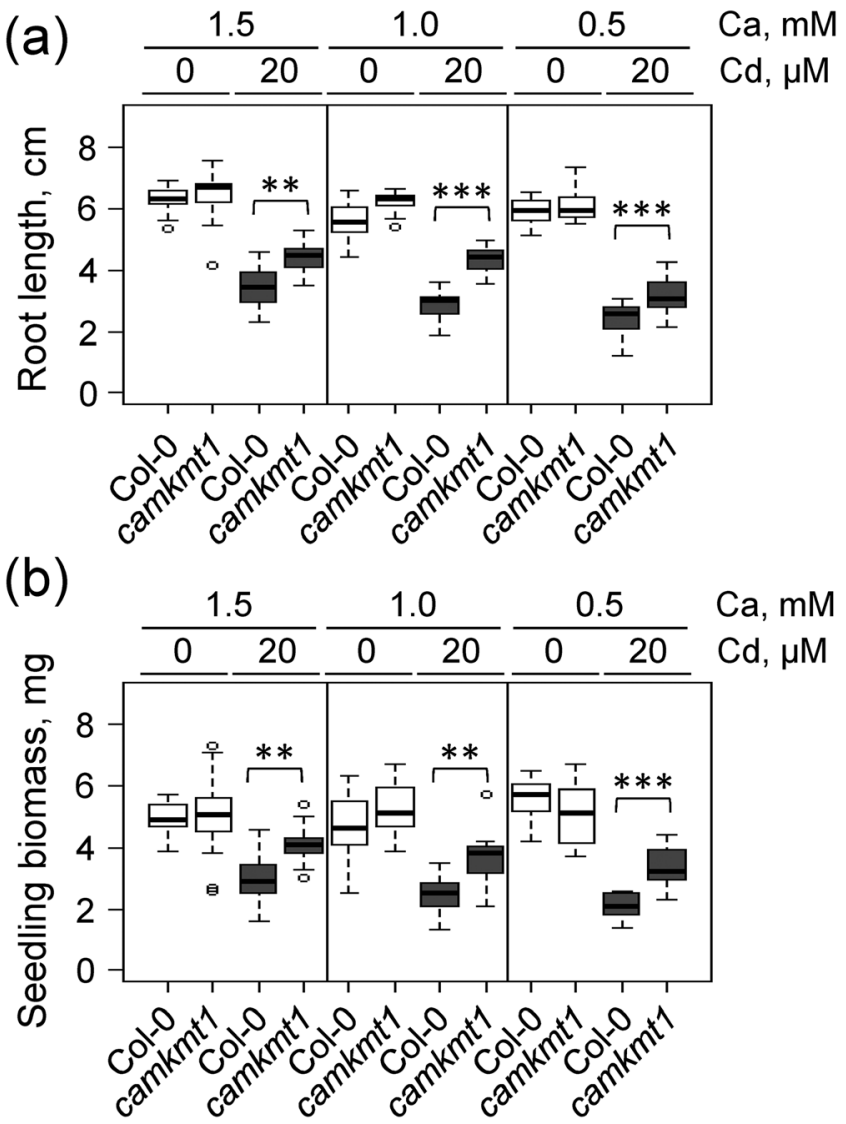

FIGURE 6 Tolerance to Cd of the calmodulin Lys methyltransferase camkmt1 mutant. Four-day-old seedlings were transferred onto $\mathrm{MS} / 2$ medium containing various amount of $\mathrm{CdSO}_{4}$ and $\mathrm{CaCl}_{2}$ and grown vertically for 10 days in photoautotrophic conditions. (a) Calcium-dependent inhibition of root growth by Cd. Root length was measured at Day 8. (b) Calcium-dependent inhibition of seedling biomass by $\mathrm{Cd}$. Seedling fresh weight was measured at Day 10. Each distribution represents $n=20$ seedlings. Statistical significance determined using a non-parametric Dunnett's test is shown, with $p$-value $<.01(* *)$, and $p$-value $<.001(* * *)$ 
(a)

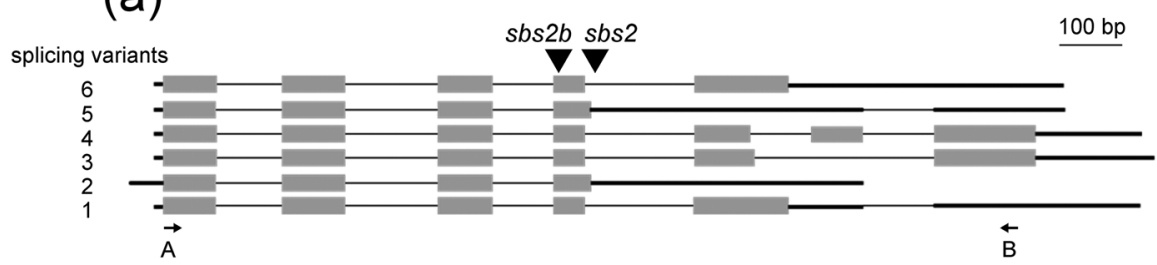

(b)

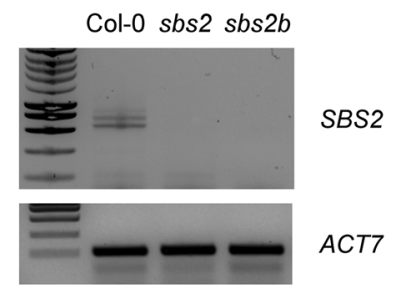

(c)

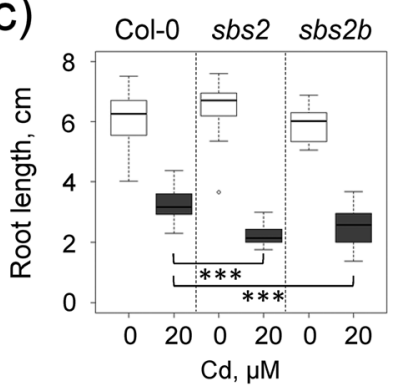

FIGURE 7 Molecular characterization of the A. thaliana sbs 2 and $s b s 2 b$ mutants. (a) Structure of the SBS2 locus. Splicing variants predicted in the Araport database are shown (https://apps.araport.org/thalemine/portal.do?externalids = AT1G63855). Thin lines represent introns, grey boxes represent exons, thick dark lines represent untranslated regions and triangles indicate T-DNA insertion sites in the sbs2 (GK-911F08) and sbs2b (SALK_037552) mutants. Primers A and B are indicated by arrows. (b) Amplification of SBS2 transcripts by PCR. PCR was performed using reverse transcribed total RNA from 10-day-old seedlings with Primers A (ATGATGACTACTACGACGACGAC) and B (CTCAATACGATCTCAACCAACTGA) for SBS2, and ACT7-F (ACATCGTTCTCAGTGGTGGTCC) and ACT7-R (ACCTGACTCATC-GTACTCACTC) for ACTIN7. PCR products were resolved by agarose gel electrophoresis. Two major amplicons of 700-800 bp were amplified in Col-0, cloned and sequenced. They correspond to splicing variants 1 and 4 . (c) Tolerance to $\mathrm{Cd}$ of the sbs 2 and $s b s 2 b$ mutants. Four-day-old seedlings were transferred onto MS/2 medium supplemented or not with $20 \mu \mathrm{M} \mathrm{CdSO}_{4}$ and grown vertically for 10 days in photoautotrophic conditions. Root length was measured at Day 8 . Each distribution represents $n=20$ seedlings. Statistical significance determined using a non-parametric Dunnett's test is shown, with $p$-value $<.001(* * *)$

Similar to camkmt1, we first confirmed the phenotype of sbs2 by measuring the inhibition of root elongation and seedling growth with different concentrations of $\mathrm{Cd}$. Root growth of sbs2 was significantly more inhibited by $\mathrm{Cd}$ than the wild type at all concentrations tested (5-20 $\mu \mathrm{M}$; Figure $5 \mathrm{c})$. Also, the biomass of sbs2 seedlings was lower than Col-0 seedlings for the three concentrations tested (Figure $5 \mathrm{~d}$ ), confirming the Cd-sensitive phenotype of sbs2.

To gain insight into the role of the SBS2 gene in the response to $\mathrm{Cd}$, we selected a second independent insertion line, referred to as sbs $2 b$. The T-DNA insertions were located in the fourth exon of SBS2 for $s b s 2 b$ and downstream the fourth exon for sbs2, in a region that is either an intron or the $3^{\prime}$ untranslated region of SBS2 transcript variants (Figure 7). Reverse transcription-PCR analysis indicated that the two lines are loss-of-function alleles with no detectable SBS2 transcripts. Also, root growth assays showed that $s b s 2 b$ behaved as sbs 2 and was less tolerant to $C d$ than wild-type seedlings (Figure 7). Together, these data indicated that the invalidation of the SBS2 gene is responsible for an increased sensitivity to $\mathrm{Cd}$.

We analysed whether the uptake and distribution of $\mathrm{Cd}$ was affected in sbs2. The $\mathrm{Cd}$ content in roots and shoots of sbs 2 was similar to that of Col-O at any Cd concentration tested (Figure S6). Thus, the increased sensitivity to $\mathrm{Cd}$ of sbs2 was not associated with an increased absorption of the toxic element from the medium but rather to a reduced capacity to deal with its deleterious effects.
Finally, as a preliminary approach to identify the substrate of the SBS2 methyltransferase, we used western blot analysis to compare the patterns of Lys-trimethylated proteins in sbs 2 and Col-0. We could not observe any significant decrease in band intensity (hypomethylation) in sbs2 relative to Col-0 in soluble or membrane proteins from roots and shoots of seedlings grown in standard conditions (Figure S7). Thus, the substrate of SBS2 is probably a low abundant protein that was not detectable by the current immunolabeling approach.

\section{DISCUSSION}

The methylation status of Lys residues in proteins is controlled by KMTs and contributes to the regulation of protein properties in diverse biological processes. To address whether Lys methylation of non-histone proteins is important for metal tolerance in Arabidopsis species, we analysed the effect of $\mathrm{Cd}$ on the two partners participating in this PTM, that is, methylated proteins on the one hand and KMTs on the other hand. Using an immunoblotting approach, we showed that the Lys-methylation status of some proteins is influenced by a $\mathrm{Cd}$ stress in the roots and leaves of Arabidopsis (Figure 1). Changes in methylation patterns were observed between Cd-tolerant and $\mathrm{Cd}$-sensitive species and between treated and untreated plants. This analysis provided the first evidence that the steady-state level of 
some methylproteins, or the stoichiometry of Lys methylation of these proteins, could be linked with metal stress and with the genetic diversity of the Arabidopsis species. Then, we used MS/MS to identify Lys-trimethylated proteins of low molecular weight (25-30 kDa) that displayed different expression profiles in the leaves of $A$. thaliana, A. lyrata or A. halleri in response to $\mathrm{Cd}$. Using a specific pipeline for the identification of Lys trimethylation events we identified 12 methyl sites in nine proteins (Table 1). Six of these proteins and eight of the Lys-methylated sites were not previously known, illustrating the depth of the analysis. In addition, by using genomic resources of $A$. lyrata for the assignment of MS/MS spectra from A. lyrata and A. halleri samples, we were able to identify, for the first time, post-translationally modified proteins in these model species.

The methylation status of only one of the identified methylproteins, RPL10A, was correlated with the different responses of Arabidopsis species upon Cd stress in leaves. RPL10A is involved in translation as a subunit of the $60 \mathrm{~S}$ large ribosomal subunit and has non-canonical functions linked with its translocation to the nucleus. RPL10A is an essential protein in plants since knockout mutants are lethal and $r p / 10 a / R P L 10 A$ heterozygous plants are deficient in translation under UV-B stress conditions (Falcone Ferreyra, Pezza, Biarc, Burlingame, \& Casati, 2010). Also, RPL10A is a substrate of the receptor-like kinase NIK1 and its phosphorylation redirects the protein from the cytosol to the nucleus where it may act to modulate viral infection (Carvalho et al., 2008). We identified two Lys trimethylation sites in Arabidopsis RPL10A proteins. The first one (Lys46) has been previously identified as monomethylated by the RKM5 methyltransferase in the homolog of RPL10A from yeast (Webb et al., 2011). Trimethylation of Lys46 was detected only in the roots of $A$. thaliana grown in control conditions and, so, has probably no link with the response to metal stress. This assumption is supported by the observation that a mutation in the SBS1 gene, the ortholog of RKM5 (Figure S5), did not change the tolerance to $\mathrm{Cd}$ of A. thaliana seedlings (Figure 4). The pattern of trimethylation of the second residue (Lys90) in RPL10A in leaves was influenced by Cd stress in a species-dependent manner (Table 1). The functional outcome of Lys90 trimethylation in RPL10A is not known; the modification may contribute to the optimization of ribosomal function or may affect its non-canonical functions, as previously showed for RPL10A phosphorylation (Carvalho et al., 2008).

We also analysed the expression of genes coding protein Lys methyltransferases in response to $\mathrm{Cd}$ in wild-type $\mathrm{A}$. thaliana and in populations of $A$. halleri with different capacities to tolerate and accumulate the toxic metal. In A. thaliana, the steady-state level of only two KMT genes is regulated by moderate concentrations of $\mathrm{Cd}$ (Table S3). In A. halleri, we showed that $\mathrm{Cd}$ induces a significant change in the expression of four KMT genes in the PL22 population, but none in the 116 population (Figure $2 \mathrm{c}$ ). The transcriptomic, ionomic and metabolomic analyses of these two metallicolous populations from different European genetic units indicated that distinct strategies driven by different sets of genes have evolved for the adaptation to high Cd (Corso et al., 2018) or high zinc in soils (Schvartzman et al., 2018). Since PL22 accumulates Cd in roots and shoots whereas $\mathrm{I} 16$ behaves as a Cd excluder, both in situ and in hydroponic conditions, these results suggest that the regulation of KMT genes expression in PL22 could be correlated with the level of $\mathrm{Cd}$ that is taken up from the environment and translocated to shoots. The substrates of the KMTs encoded by these four genes (SDG52, SBS2, SBS5 and SBS9) are likely not histones (Figure S5), suggesting that Lys methylation of non-histone proteins could contribute to the regulation of cellular mechanisms involved in $\mathrm{Cd}$ accumulation or detoxification in the PL22 population. The analysis of DEGs between 116 and PL22, regardless of the presence of $\mathrm{Cd}$ in the culture medium, identified 22 KMT genes (Figure 2b). This suggests that Lys methylation of histones and non-histone substrates could be part of the diverging adaptation strategies of metallicolous populations. The expression of KMT genes coding enzymes of the SDG family has been previously analysed in cotton plants stressed with high temperature (Huang et al., 2016) and in foxtail millet under different abiotic stresses (Yadav, Muthamilarasan, Dangi, Shweta, \& Prasad, 2016). In these studies, the expression pattern of some KMT genes was significantly changed in stress conditions. These data, together with our results, suggest that protein Lys methylation could play a role in the responses of plants to a variety of abiotic stresses.

Finally, we used a screening procedure based on root growth inhibition assays to determine whether some KMT genes could be important for A. thaliana to cope with $\mathrm{Cd}$. We showed that 9 out of 23 insertion mutants displayed a tolerance to $\mathrm{Cd}$ that was significantly different from that of wild-type seedlings (Figure 4). These KMTs belong to the SDG class VII (SDG50, SDG51 SDG52) and to the SBS family (SBS2, SBS6, SBS7, SBS8, SBS9 CaMKMT) and are known, or predicted, to modify non-histone targets (Serre et al., 2018), suggesting that Lys methylation of non-histone proteins is one of the regulatory mechanisms modulating the response of $A$. thaliana to $C d$ stress.

Two of the identified mutants were further investigated. The camkmt1 line is unable to methylate CaM (Banerjee et al., 2013) and is more tolerant to $\mathrm{Cd}$ than the wild type at each $\mathrm{Ca}$ concentration tested (Figure 5). Cadmium is known to interfere with $\mathrm{Ca}$ homeostasis and the $\mathrm{Ca} / \mathrm{CaM}$ system has been hypothesized to participate in heavy metal signalling (Baliardini et al., 2015; Gallego et al., 2012). More generally, CaM has been implicated in the response and recovery to different stresses and CaM methylation has been proposed to play a regulatory role in these processes. Indeed, a camkmt1 null mutant displayed increased tolerance to salt, heat and cold stress whereas lines overexpressing CAMKMT were hypersensitive to these stresses (Banerjee et al., 2013). Together, these data suggest that Lys methylation of $\mathrm{CaM}$ also plays a role in the signalling cascade triggered by $\mathrm{Cd}$, probably at a level that is common between different abiotic stresses. The precise role of Lys methylation in the modulation of CaM activity is still unclear.

Our data also indicated that the invalidation of the SBS2 gene in A. thaliana is associated with a decreased capacity to cope with $\mathrm{Cd}$ (Figure 7). Also, the expression of SBS2 was increased in the roots of A. halleri PL22 plants challenged with $\mathrm{Cd}$ (Figure 2c), suggesting that the methylation reaction catalysed by SBS2 is useful to limit the deleterious effects of $\mathrm{Cd}$. The function of SBS2 is still not known in plants. 
Its ortholog in animal cells is METTL23 (Figure S5). METTL23 is located in the cytoplasm and the nucleus, interacts with a subunit of the GA-binding protein transcription factor, but its target(s) has not been yet identified (Bernkopf et al., 2014; Reiff et al., 2014). The profiling of methylproteins in sbs 2 and Col-0 by western blot was not sensitive enough to detect any change between the two lines (Figure S7), providing no clues to the nature of the substrate(s) of the SBS2 enzyme. The identification of the target(s) of SBS2 is the next step to gain insight into the role of this methylation event under favourable growth conditions and in the response to $\mathrm{Cd}$ stress.

Together, the data presented in this study provide the first evidence for a link between the methylation status of Lys in non-histone proteins and the response of plants to a stress induced by $\mathrm{Cd}$. They pave the way for the identification of cellular mechanisms that are regulated by protein Lys methylation and are important for plants to cope with toxic elements. To reach this goal one has to identify the $\mathrm{KMT} /$ substrate relationships to be able to modulate the methylation status of protein targets in vivo. To summarize, this work suggests that the characterization of the KMT involved in the methylation of Lys90 in RPL10A and the identification of the substrates of the KMTs encoded by genes that are modulated by $\mathrm{Cd}$ and play a role in $\mathrm{Cd}$ tolerance will provide significant insights into the role of protein Lys methylation during metal stress.

\section{ACKNOWLEDGMENTS}

This work was supported by grants from the Région Auvergne RhôneAlpes (PhD to N.B.C.S.), the Fondation de Coopération Scientifique Rovaltain (PlantStressMetalPTMs project), the Toxicology Program of the Commissariat à l'Energie Atomique et aux Energies Alternatives, the Department of Plant Biology and Breeding of the Institut National de la Recherche Agronomique, the LabEx GRAL (ANR-10-LABX-49-01) and the Fonds de la Recherche Scientifique-FNRS (PDR T.0206.13 to N.V.). This article is dedicated to the memory of Professor Roland Douce.

\section{AUTHOR CONTRIBUTIONS}

N.B.C.S., V.S., N.V. and S.R. conceived and designed the study; N.B.C.S., M.S., O.G., S.F., M.C., J.C., V.R. and S.R. performed the experiments; N.B.C.S., M.S., O.G., M.C., V.R., C.A., V.S., J.B., N.V. and S.R. analysed the data; N.B.C.S. and S.R. wrote the paper, with the input from all co-authors.

\section{ORCID}

Nelson B. C. Serre (iD) https://orcid.org/0000-0003-3585-1537 Massimiliano Corso (D) https://orcid.org/0000-0003-3025-8785 Véronique Santoni (D) https://orcid.org/0000-0002-1437-0921 Jacques Bourguignon (D) https://orcid.org/0000-0001-7517-0600 Nathalie Verbruggen (D) https://orcid.org/0000-0003-2296-5404 Stéphane Ravanel (iD) https://orcid.org/0000-0001-9475-4222

\section{REFERENCES}

Alban, C., Tardif, M., Mininno, M., Brugiere, S., Gilgen, A., Ma, S., ... Ravanel, S. (2014). Uncovering the protein lysine and arginine methylation network in Arabidopsis chloroplasts. PLoS One, 9, e95512.
Baliardini, C., Meyer, C. L., Salis, P., Saumitou-Laprade, P., \& Verbruggen, N. (2015). CATION EXCHANGER1 cosegregates with cadmium tolerance in the metal hyperaccumulator Arabidopsis halleri and plays a role in limiting oxidative stress in Arabidopsis Spp. Plant Physiology, 169, 549-559.

Banerjee, J., Magnani, R., Nair, M., Dirk, L. M., DeBolt, S., Maiti, I. B., \& Houtz, R. L. (2013). Calmodulin-mediated signal transduction pathways in Arabidopsis are fine-tuned by methylation. Plant Cell, 25, 4493-4511.

Bernkopf, M., Webersinke, G., Tongsook, C., Koyani, C. N., Rafiq, M. A., Ayaz, M., ... Duba, H. C. (2014). Disruption of the methyltransferaselike 23 gene METTL23 causes mild autosomal recessive intellectual disability. Human Molecular Genetics, 23, 4015-4023.

Carroll, A. J., Heazlewood, J. L., Ito, J., \& Millar, A. H. (2008). Analysis of the Arabidopsis cytosolic ribosome proteome provides detailed insights into its components and their post-translational modification. Molecular \& Cellular Proteomics, 7, 347-369.

Carvalho, C. M., Santos, A. A., Pires, S. R., Rocha, C. S., Saraiva, D. I., Machado, J. P., ... Fontes, E. P. (2008). Regulated nuclear trafficking of rpL10A mediated by NIK1 represents a defense strategy of plant cells against virus. PLoS Pathogens, 4, e1000247.

Clemens, S., Aarts, M. G., Thomine, S., \& Verbruggen, N. (2013). Plant science: The key to preventing slow cadmium poisoning. Trends in Plant Science, 18, 92-99.

Clemens, S., \& Ma, J. F. (2016). Toxic heavy metal and metalloid accumulation in crop plants and foods. Annual Review of Plant Biology, 67, 489-512.

Corso, M., Schvartzman, M. S., Guzzo, F., Souard, F., Malkowski, E., Hanikenne, M., \& Verbruggen, N. (2018). Contrasting cadmium resistance strategies in two metallicolous populations of Arabidopsis halleri. New Phytologist, 218, 283-297.

Dahan, J., Koen, E., Dutartre, A., Lamotte, O., \& Bourque, S. (2011). Posttranslational modifications of nuclear proteins in the response of plant cells to abiotic stresses. In A. Shanker (Ed.), Abiotic stress response in plants - physiological, biochemical and genetic perspectives (pp. 77-112). Rijeka, Croatia: InTech.

DalCorso, G., Fasani, E., \& Furini, A. (2013). Recent advances in the analysis of metal hyperaccumulation and hypertolerance in plants using proteomics. Frontiers in Plant Science, 4, 280.

Falcone Ferreyra, M. L., Pezza, A., Biarc, J., Burlingame, A. L., \& Casati, P. (2010). Plant L10 ribosomal proteins have different roles during development and translation under ultraviolet-B stress. Plant Physiology, 153, 1878-1894.

Falnes, P. O., Jakobsson, M. E., Davydova, E., Ho, A., \& Malecki, J. (2016). Protein lysine methylation by seven-beta-strand methyltransferases. Biochemical Journal, 473, 1995-2009.

Fischer, S., Spielau, T., \& Clemens, S. (2017). Natural variation in Arabidopsis thaliana $\mathrm{Cd}$ responses and the detection of quantitative trait loci affecting Cd tolerance. Scientific Reports, 7, 3693.

Gallego, S. M., Pena, L. B., Barcia, R. A., Azpilicueta, C. E., Lannone, M. F., Rosales, E. P., ... Benavides, M. P. (2012). Unravelling cadmium toxicity and tolerance in plants: Insight into regulatory mechanisms. Environmental and Experimental Botany, 83, 33-46.

Grubler, B., Merendino, L., Twardziok, S. O., Mininno, M., Allorent, G. Chevalier, F., ... Pfannschmidt, T. (2017). Light and plastid signals regulate different sets of genes in the albino mutant pap7-1. Plant Physiology, 175, 1,203-1,219.

Gzyl, J., Chmielowska-Bak, J., Przymusinski, R., \& Gwozdz, E. A. (2015). Cadmium affects microtubule organization and post-translational modifications of tubulin in seedlings of soybean (Glycine max L.). Frontiers in Plant Science, 6, 937.

Haak, D. C., Fukao, T., Grene, R., Hua, Z., Ivanov, R., Perrella, G., \& Li, S. (2017). Multilevel regulation of abiotic stress responses in plants. Frontiers in Plant Science, 8, 1564.

Hart-Smith, G., Yagoub, D., Tay, A. P., Pickford, R., \& Wilkins, M. R. (2016). Large scale mass spectrometry-based identifications of enzyme- 
mediated protein methylation are subject to high false discovery rates. Molecular \& Cellular Proteomics, 15, 989-1006.

Herbette, S., Taconnat, L., Hugouvieux, V., Piette, L., Magniette, M. L., Cuine, S., ... Leonhardt, N. (2006). Genome-wide transcriptome profiling of the early cadmium response of Arabidopsis roots and shoots. Biochimie, 88, 1751-1765.

Howden, R., Andersen, C. R., Goldsbrough, P. B., \& Cobbett, C. S. (1995). A cadmium-sensitive, glutathione-deficient mutant of Arabidopsis thaliana. Plant Physiology, 107, 1067-1073.

Hu, T. T., Pattyn, P., Bakker, E. G., Cao, J., Cheng, J. F., Clark, R. M., ... Guo, Y. L. (2011). The Arabidopsis lyrata genome sequence and the basis of rapid genome size change. Nature Genetics, 43, 476-481.

Huang, Y., Mo, Y., Chen, P., Yuan, X., Meng, F., Zhu, S., \& Liu, Z. (2016). Identification of SET domain-containing proteins in Gossypium raimondii and their response to high temperature stress. Scientific Reports, 6, 32729.

Janicka-Russak, M., Kabala, K., \& Burzynski, M. (2012). Different effect of cadmium and copper on $\mathrm{H}+$-ATPase activity in plasma membrane vesicles from Cucumis sativus roots. Journal of Experimental Botany, 63, 4133-4142.

Jobe, T. O., Sung, D. Y., Akmakjian, G., Pham, A., Komives, E. A., MendozaCozatl, D. G., \& Schroeder, J. I. (2012). Feedback inhibition by thiols outranks glutathione depletion: A luciferase-based screen reveals glutathione-deficient gamma-ECS and glutathione synthetase mutants impaired in cadmium-induced sulfate assimilation. Plant Journal, 70, 783-795.

Jonak, C., Nakagami, H., \& Hirt, H. (2004). Heavy metal stress. Activation of distinct mitogen-activated protein kinase pathways by copper and cadmium. Plant Physiology, 136(3), 276-3283.

Khare, D., Mitsuda, N., Lee, S., Song, W. Y., Hwang, D., Ohme-Takagi, M., ... Hwang, J. U. (2017). Root avoidance of toxic metals requires the GeBP-LIKE 4 transcription factor in Arabidopsis thaliana. New Phytologist, 213, 1257-1273.

Konietschke, F., Placzek, M., Schaarschmidt, F., \& Hothorn, L. A. (2015). nparcomp: An R software package for nonparametric multiple comparisons and simultaneous confidence intervals. Journal of Statistical Software, 64, 1-17.

Kosova, K., Vitamvas, P., Prasil, I. T., \& Renaut, J. (2011). Plant proteome changes under abiotic stress - Contribution of proteomics studies to understanding plant stress response. Journal of Proteomics, 74, 1301-1322.

Kramer, U. (2010). Metal hyperaccumulation in plants. Annual Review of Plant Biology, 61, 517-534.

Kulik, A., Anielska-Mazur, A., Bucholc, M., Koen, E., Szymanska, K., Zmienko, A., ... Dobrowolska, G. (2012). SNF1-related protein kinases type 2 are involved in plant responses to cadmium stress. Plant Physiology, 160, 868-883.

Lanouette, S., Mongeon, V., Figeys, D., \& Couture, J. F. (2014). The functional diversity of protein lysine methylation. Molecular Systems Biology, 10, 724.

Le, S. Q., \& Gascuel, O. (2008). An improved general amino acid replacement matrix. Molecular Biology and Evolution, 25, 1307-1320.

Li, J. Y., Fu, Y. L., Pike, S. M., Bao, J., Tian, W., Zhang, Y., ... Gong, J. M. (2010). The Arabidopsis nitrate transporter NRT1.8 functions in nitrate removal from the xylem sap and mediates cadmium tolerance. Plant Cell, 22(1), 633-1646.

Liu, X. M., Kim, K. E., Kim, K. C., Nguyen, X. C., Han, H. J., Jung, M. S., ... Chung, W. S. (2010). Cadmium activates Arabidopsis MPK3 and MPK6 via accumulation of reactive oxygen species. Phytochemistry, 71, 614-618.

Lopez-Valenzuela, J. A., Gibbon, B. C., Hughes, P. A., Dreher, T. W., \& Larkins, B. A. (2003). eEF1A Isoforms change in abundance and Actinbinding activity during maize endosperm development. Plant Physiology, 133, 1285-1295.

Ma, S., Martin-Laffon, J., Mininno, M., Gigarel, O., Brugiere, S., Bastien, O., ... Alban, C. (2016). Molecular evolution of the substrate specificity of chloroplastic aldolases/Rubisco lysine methyltransferases in plants. Molecular Plant, 9, 569-581.

Mazzoleni, M., Figuet, S., Martin-Laffon, J., Mininno, M., Gilgen, A., Leroux, M., ... Ravanel, S. (2015). Dual targeting of the protein Methyltransferase PrmA contributes to both Chloroplastic and mitochondrial ribosomal protein L11 methylation in Arabidopsis. Plant and Cell Physiology, 56, 1697-1710.

Metwally, A., Safronova, V. I., Belimov, A. A., \& Dietz, K. J. (2005). Genotypic variation of the response to cadmium toxicity in Pisum sativum $L$. Journal of Experimental Botany, 56, 167-178.

Meyer, C. L., Juraniec, M., Huguet, S., Chaves-Rodriguez, E., Salis, P., Isaure, M. P., ... Verbruggen, N. (2015). Intraspecific variability of cadmium tolerance and accumulation, and cadmium-induced cell wall modifications in the metal hyperaccumulator Arabidopsis halleri. Journal of Experimental Botany, 66, 3215-3227.

Mininno, M., Brugiere, S., Pautre, V., Gilgen, A., Ma, S., Ferro, M., ... Ravanel, S. (2012). Characterization of chloroplastic fructose 1,6-bisphosphate aldolases as lysine-methylated proteins in plants. Journal of Biological Chemistry, 287, 21034-21044.

Moulis, J. M., Bourguignon, J., \& Catty, P. (2014). Cadmium. In Binding, transport and storage of metal ions in biological cells (pp. 695-746). Cambridge, UK: Royal Society of Chemistry.

Ndamukong, I., Lapko, H., Cerny, R. L., \& Avramova, Z. (2011). A cytoplasm-specific activity encoded by the Trithorax-like ATX1 gene. Nucleic Acids Research, 39, 4709-4718.

Ong, S. E., Mittler, G., \& Mann, M. (2004). Identifying and quantifying in vivo methylation sites by heavy methyl SILAC. Nature Methods, 1, 119-126.

Pena, L. B., Barcia, R. A., Azpilicueta, C. E., Mendez, A. A., \& Gallego, S. M. (2012). Oxidative post translational modifications of proteins related to cell cycle are involved in cadmium toxicity in wheat seedlings. Plant Sci, 196, 1-7.

Pena, L. B., Pasquini, L. A., Tomaro, M. L., \& Gallego, S. M. (2006). Proteolytic system in sunflower (Helianthus annuus L.) leaves under cadmium stress. Plant Science, 171, 531-537.

Polge, C., Jaquinod, M., Holzer, F., Bourguignon, J., Walling, L., \& Brouquisse, R. (2009). Evidence for the existence in Arabidopsis thaliana of the proteasome proteolytic pathway: Activation in response to cadmium. Journal of Biological Chemistry, 284, 35412-35424.

Rawat, V., Abdelsamad, A., Pietzenuk, B., Seymour, D. K., Koenig, D., Weigel, D., ... Schneeberger, K. (2015). Improving the annotation of Arabidopsis lyrata using RNA-seq data. PLoS One, 10, e0137391.

Reiff, R. E., Ali, B. R., Baron, B., Yu, T. W., Ben-Salem, S., Coulter, M. E., ... Mochida, G. H. (2014). METTL23, a transcriptional partner of GABPA, is essential for human cognition. Human Molecular Genetics, 23, 3456-3466.

Remy, E., \& Duque, P. (2016). Assessing tolerance to heavy-metal stress in Arabidopsis thaliana seedlings. Methods in Molecular Biology, 1(398), 197-208.

Romero-Puertas, M. C., Palma, J. M., Gómez, M., Del Río, L. A., \& Sandalio, L. M. (2002). Cadmium causes the oxidative modification of proteins in pea plants. Plant, Cell \& Environment, 25, 677-686.

Sarry, J. E., Kuhn, L., Ducruix, C., Lafaye, A., Junot, C., Hugouvieux, V., ... Bourguignon, J. (2006). The early responses of Arabidopsis thaliana cells to cadmium exposure explored by protein and metabolite profiling analyses. Proteomics, 6, 2180-2198.

Schvartzman, M. S., Corso, M., Fataftah, N., Scheepers, M., Nouet, C., Bosman, B., ... Hanikenne, M. (2018). Adaptation to high zinc depends on distinct mechanisms in metallicolous populations of Arabidopsis halleri. New Phytologist, 218, 269-282.

Serre, N. B. C., Alban, C., Bourguignon, J., \& Ravanel, S. (2018). An outlook on lysine methylation of non-histone proteins in plants. Journal of Experimental Botany, 69, 4569-4581.

Shechter, D., Dormann, H. L., Allis, C. D., \& Hake, S. B. (2007). Extraction, purification and analysis of histones. Nature Protocols, 2, 1445-1457. 
Sormani, R., Delannoy, E., Lageix, S., Bitton, F., Lanet, E., Saez-Vasquez, J., ... Robaglia, C. (2011). Sublethal cadmium intoxication in Arabidopsis thaliana impacts translation at multiple levels. Plant and Cell Physiology, $52,436-447$

Stein, R. J., Horeth, S., de Melo, J. R., Syllwasschy, L., Lee, G., Garbin, M. L., ... Kramer, U. (2017). Relationships between soil and leaf mineral composition are element-specific, environment-dependent and geographically structured in the emerging model Arabidopsis halleri. New Phytologist, 213, 1274-1286.

Suzuki, N. (2005). Alleviation by calcium of cadmium-induced root growth inhibition in Arabidopsis seedlings. Plant Biotechnology, 22, 19-25.

Tamura, K., Stecher, G., Peterson, D., Filipski, A., \& Kumar, S. (2013). MEGA6: Molecular evolutionary genetics analysis version 6.0. Molecular Biology and Evolution, 30(2), 725-2729.

Verbruggen, N., Hermans, C., \& Schat, H. (2009). Molecular mechanisms of metal hyperaccumulation in plants. New Phytologist, 181, 759-776.

Verbruggen, N., Juraniec, M., Baliardini, C., \& Meyer, C. L. (2013). Tolerance to cadmium in plants: The special case of hyperaccumulators. Biometals, 26, 633-638.

Villiers, F., Ducruix, C., Hugouvieux, V., Jarno, N., Ezan, E., Garin, J., ... Bourguignon, J. (2011). Investigating the plant response to cadmium exposure by proteomic and metabolomic approaches. Proteomics, 11, 1650-1663.

Wang, Q., Wang, K., \& Ye, M. (2017). Strategies for large-scale analysis of non-histone protein methylation by LC-MS/MS. Analyst, 142, 3536-3548.
Webb, K. J., Al-Hadid, Q., Zurita-Lopez, C. I., Young, B. D., Lipson, R. S., \& Clarke, S. G. (2011). The ribosomal I1 protuberance in yeast is methylated on a lysine residue catalyzed by a seven-beta-strand methyltransferase. Journal of Biological Chemistry, 286, 18405-18413.

Weber, M., Trampczynska, A., \& Clemens, S. (2006). Comparative transcriptome analysis of toxic metal responses in Arabidopsis thaliana and the $\mathrm{Cd}(2+)$-hypertolerant facultative metallophyte Arabidopsis halleri. Plant Cell Environment, 29, 950-963.

Yadav, C. B., Muthamilarasan, M., Dangi, A., Shweta, S., \& Prasad, M. (2016). Comprehensive analysis of SET domain gene family in foxtail millet identifies the putative role of SiSET14 in abiotic stress tolerance. Scientific Reports, 6, 32,621.

\section{SUPPORTING INFORMATION}

Additional supporting information may be found online in the Supporting Information section at the end of this article.

How to cite this article: Serre NBC, Sarthou M, Gigarel O, et al. Protein lysine methylation contributes to modulating the response of sensitive and tolerant Arabidopsis species to cadmium stress. Plant Cell Environ. 2020;43:760-774. https:// doi.org/10.1111/pce.13692 